Research Report

\title{
PREVALENCE OF MAJOR DEPRESSIVE DISORDER AMONG WIVES OF MEN WITH ALCOHOL USE DISORDER-A CROSS-SECTIONAL STUDY FROM A TERTIARY CARE HOSPITAL
}

\author{
Thilakan Vijunath ${ }^{1}$, Sivasubramoney Krishnan², Mili Babu* \\ ${ }^{1}$ Sree Narayana Institute of Medical Sciences, Ernakulam, Kerala, India \\ ${ }^{2}$ Government Medical College, Alappuzha, Kerala, India \\ ${ }^{3}$ Government Medical College, Thiruvananthapuram, Kerala, India \\ ${ }^{*}$ Corresponding address: Assistant Professor In Psychiatry, Government Medical College, Thiruvananthapuram, Kerala, India \\ - 695011. Email:drmili.babu@gmail.com
}

\begin{abstract}
Background: Alcohol Use Disorder is highly prevalent in India. Alcohol acts as a continuous stressor, with several stressful consequences on the wife. Literature suggests an association between alcohol use in the husband and depression in the wife. Objectives: The primary objective was to assess the prevalence of Major Depressive Disorder(MDD) among wives of men with Alcohol Use Disorder attending the Psychiatry Department in a tertiary care centre. The secondary objective was to assess various sociodemographic and clinical variables associated with depressive disorder in the wives. Methods: A cross-sectional study was done on wives of men diagnosed with Alcohol Use Disorder while attending the outpatient clinic or inpatient treatment at the Psychiatry Department. Consecutive sampling was done till the calculated sample size of 133 was reached. PHQ 9 was administered to the wives to assess Depressive Disorder with a cutoff score of 10. Statistical analysis was done using the Chi-square test. Odds Ratio and confidence intervals were calculated to determine the strength of associations. Results: Prevalence of Major Depressive Disorder in the study population was found to be $27.8 \%$. A significant association was found between the severity of Alcohol Use Disorder and depression in wives $(\mathrm{OR}=4.01,95 \% \mathrm{CI}=1.4411 .22, \mathrm{p}<0.01)$. Morning drinking among husbands was significantly associated with depression in wives $(\mathrm{OR}=4.32,95 \% \mathrm{CI}=1.32-19.56, \mathrm{p}=0.04)$. Conclusion: Prevalence of Major Depressive Disorder among wives of men with Alcohol Use Disorder was high. Depressive disorder in wives significantly correlated with the severity of Alcohol Use Disorder and the husbands' morning drinking. Hence wives of men with Alcohol Use Disorder should be routinely screened for depression, and necessary interventions should be given promptly.
\end{abstract}

Keywords: Major Depressive Disorder, Alcohol Use Disorder, wives

\section{INTRODUCTION}

Alcohol Use Disorder causes a wide spectrum of physical and mental health problems. ${ }^{1}$ Nearly $27.3 \%$ of the Indian male population consumes alcohol. ${ }^{2}$ The prevalence of alcohol use varies across different parts of the country. ${ }^{3}$ Several studies have reported that the rate

Access the article online:

https://kjponline.com/index.php/kjp/article/view/238

DOI: https://doi.org/10.30834/KJP.34.1.2021.238

Received: 28/12/2020. Accepted: 14/04/2021.

Web publication: $25 / 04 / 2021$ of alcohol consumption in the South Indian state of Kerala is higher than the national rate. ${ }^{4,5,6}$ Hence there is a revived interest in studies on alcohol and its related problems in Kerala.

In the family context, the wife of the man with alcohol use disorder experiences high stress levels and low

Please cite this article as: Thilakan V, Sivasubramoney K and Babu M. Prevalence of major depressive disorder among wives of men with alcohol use disorder-a crosssectional study from a tertiary care hospital. Kerala Tournal of Psvchiatrv 2021:34(1): 1-6 
quality of life. ${ }^{7,8}$ She is subjected to multiple stressors such as emotional and physical abuse, financial issues and increased risk of separation or divorce. ${ }^{7,8}$ Studies indicate that spouses of men with alcohol use disorder experience higher rates of depressive, anxiety and stress-related disorders., ${ }^{90,11}$

Identifying depression in the spouse of the person with Alcohol Use Disorder is important because she plays a significant role in treatment strategies for her husband. ${ }^{10}$ A Sri Lankan study conducted in rural communities of Lanka concluded that on average, one in three women whose husbands used alcohol had Major Depressive Disorder. $^{12}$

A descriptive study conducted by Kishore et al. ${ }^{13}$ in India showed a $43 \%$ prevalence of Major Depressive Disorder among spouses of men with Alcohol Dependence Syndrome. Depression also had a significant correlation with the severity of alcohol use. ${ }^{13}$

A study conducted in Goa in 2010 concluded that there is an increased prevalence of common mental health problems like depression in women whose husbands used alcohol. ${ }^{11}$

Despite high prevalence rates for Alcohol Use Disorders $^{4}$ and Depressive Disorders ${ }^{15}$ in Kerala, there is a dearth of studies on depression in the spouse of a person with Alcohol Use Disorder.

\section{OBJECTIVES}

\section{Primary Objective}

To estimate the prevalence of Major Depressive Disorder among wives of men with Alcohol Use Disorder attending the outpatient clinic or admitted as an inpatient in the Psychiatry Department of a tertiary care teaching institute.

\section{Secondary Objective}

To study the association of various sociodemographic and clinical variables with Major Depressive Disorder in the wives of men with Alcohol Use Disorder

\section{MATERIALS AND METHODS}

This cross-sectional observational study was done at the outpatient clinic and the inpatient wards of the Department Of Psychiatry of Government Medical College, Thiruvananthapuram in Kerala. The approval of the Institutional Research Committee and the Institutional Ethics Committee was obtained. The study period was one year, from January 2017 to December 2017.

The sample size was calculated based on the formula $\mathrm{N}=4 \mathrm{pq} / \mathrm{d}^{2} \quad$ where $\mathrm{p}$ is the proportion of Major depressive Disorder from a previous study ${ }^{13} \mathrm{~W}$ ith $\mathrm{p}=43$, $q=100-p=57 ; d=20 \%$ of $p$, the calculated sample size was 133. Consecutive cases meeting the inclusion criteria were recruited till an adequate sample size was reached.

\section{Inclusion Criteria}

Women aged 18-55 years whose husbands were clinically diagnosed with Alcohol Use Disorder as per DSM 5 criteria were included in the study. Those who did not give consent were excluded.

\section{Procedure}

The wives of patients already diagnosed with Alcohol Use Disorder as per DSM- $5^{16}$ criteria were invited to participate in the study. Those who satisfied the study criteria were enrolled into the study after collecting a written informed consent. Sociodemographic and clinical details were collected in a semi-structured proforma. Depression in the study population was assessed using the PHQ-9 Questionnaire. ${ }^{17}$, 18 For this study, a cut-off score of 10 was taken for diagnosing Major Depressive Disorder. Those who scored positive for depression were subclassified based on PHQ 9 score as follows:

Major Depressive Disorder Mild- 10-14

Major Depressive Disorder Moderate- 15-19

Major Depressive Disorder Severe- 20-27

Categorical variables were presented as frequencies and percentages. The data collected were analyzed using SPSS version 20. Comparison of proportions was made by using the Chi-Square test. Odds ratio and their confidence intervals were calculated to determine the strength of the associations

\section{RESULTS}

In the study, 133 males were diagnosed to have Alcohol Use Disorder and their spouses were evaluated. $61 \%$ of the males were below 40 years, with a mean age of 44.3 years. $43 \%$ of the husbands were unskilled labourers, or unemployed $.57 \%$ had skilled or semiskilled jobs. The majority (97\%) of the men had a monthly income of less than 5000 rupees. $43.6 \%$ consumed an average of 181- 
$375 \mathrm{ml}$ of alcohol. $85 \%$ consumed alcohol daily. (Table 1)

Table 1. Background variables of subjects with AUD.( $\mathrm{N}=133$ )

\begin{tabular}{|c|c|c|c|}
\hline \multicolumn{2}{|c|}{ Variables } & Frequency & $\%$ \\
\hline \multirow{3}{*}{ Age } & Above 40 years & 52 & 39 \\
\hline & Below 40 years & 81 & 61 \\
\hline & $\begin{array}{l}\text { Above high } \\
\text { school }\end{array}$ & 95 & 71.4 \\
\hline Education & $\begin{array}{l}\text { Below high } \\
\text { School }\end{array}$ & 38 & 28.5 \\
\hline \multirow[t]{2}{*}{ Occupation } & $\begin{array}{l}\text { Semiskilled } \\
\text { and skilled }\end{array}$ & 76 & 57.1 \\
\hline & $\begin{array}{l}\text { Unemployed } \\
\text { or unskilled }\end{array}$ & 57 & 42.8 \\
\hline \multirow{2}{*}{ Religion } & Hindu & 111 & 83.4 \\
\hline & others & 22 & 16.5 \\
\hline \multirow{2}{*}{ Income } & Above 5000 & 4 & 3 \\
\hline & below 5000 & 129 & 97 \\
\hline \multirow{2}{*}{ Alcohol Use } & Above 5 years & 123 & 92.5 \\
\hline & below 5 years & 10 & 7.5 \\
\hline \multirow{2}{*}{$\begin{array}{l}\text { Quantity of } \\
\text { alcohol }\end{array}$} & Above $375 \mathrm{ml}$ & 56 & 42 \\
\hline & below $375 \mathrm{ml}$ & 77 & 58 \\
\hline \multirow{2}{*}{ Daily Drinking } & Yes & 113 & 85 \\
\hline & No & 20 & 15 \\
\hline \multirow{2}{*}{$\begin{array}{l}\text { Morning } \\
\text { Drinking }\end{array}$} & Yes & 112 & 84.21 \\
\hline & No & 21 & 15.8 \\
\hline \multirow{2}{*}{$\begin{array}{l}\text { Withdrawal } \\
\text { Symptoms }\end{array}$} & Yes & 120 & 90.2 \\
\hline & No & 13 & 9.8 \\
\hline \multirow{2}{*}{ Medical Illness } & Yes & 73 & 54.9 \\
\hline & No & 60 & 45.1 \\
\hline \multirow{2}{*}{$\begin{array}{l}\text { Psychiatric } \\
\text { Illness }\end{array}$} & Yes & 34 & 25.56 \\
\hline & No & 99 & 74.43 \\
\hline \multirow{2}{*}{$\begin{array}{l}\text { Years of } \\
\text { marriage }\end{array}$} & Above 20 years & 47 & 35.33 \\
\hline & below 20 years & 86 & 64.66 \\
\hline \multirow{2}{*}{ Legal issues } & Yes & 19 & 14.3 \\
\hline & No & 114 & 85.7 \\
\hline \multirow{2}{*}{$\begin{array}{l}\text { Severity of } \\
\text { alcohol Use }\end{array}$} & Severe & 91 & 68.4 \\
\hline & $\begin{array}{l}\text { Mild and } \\
\text { Moderate }\end{array}$ & 42 & 31.6 \\
\hline
\end{tabular}

Morning drinking was reported in $84.2 \%$. Withdrawal symptoms were reported in $90.2 \%$ of the males. $92.5 \%$ had a history of alcohol use of more than five years.14.3\% had alcohol-related legal issues (Table 1). 68.4\% had severe Alcohol Use Disorder, 22.6\% had moderate, while $9 \%$ had mild Alcohol Use Disorder.

The variables assessed in the wives were age, religion, and occupation, presence of thyroid disease, intake of medications, history of deliberate self-harm, family history of mood disorder and history of physical abuse. The majority of women belonged to the less than 40 years group (63.1\%) with a mean age of 38.7 years.61\% were housewives. $12.8 \%$ reported a history of thyroid disease. In contrast, $11.3 \%$ reported taking medications for physical illness., $36.1 \%$ reported a history of physical abuse $10.5 \%$ of the women had attained menopause. $9 \%$ had a history of mood disorder. (Table 2)

Table 2. Background variables of wives of subjects with AUD $(\mathrm{N}=133)$

\begin{tabular}{|c|c|c|c|}
\hline Variables & & Frequency & $\%$ \\
\hline \multirow{2}{*}{ Age } & above 40 & 49 & 36.9 \\
\hline & below 40 & 84 & 63.1 \\
\hline \multirow{2}{*}{ Occupation } & Housewife & 81 & 60.9 \\
\hline & others & 52 & 39.1 \\
\hline \multirow{2}{*}{ Religion } & Hindu & 113 & 85 \\
\hline & others & 20 & 15 \\
\hline \multirow{2}{*}{ Thyroid Dysfunction } & Yes & 17 & 12.8 \\
\hline & No & 116 & 87.2 \\
\hline \multirow{2}{*}{ Medications } & Yes & 15 & 11.3 \\
\hline & No & 118 & 88.7 \\
\hline \multirow{2}{*}{$\begin{array}{l}\text { Family history of } \\
\text { mood disorder }\end{array}$} & Yes & 12 & 9 \\
\hline & No & 121 & 91 \\
\hline \multirow{2}{*}{ Menopause } & Yes & 14 & 10.5 \\
\hline & No & 119 & 89.5 \\
\hline \multirow{2}{*}{$\begin{array}{l}\text { History of Deliberate } \\
\text { Self Harm }\end{array}$} & Yes & 16 & 12 \\
\hline & No & 117 & 88 \\
\hline \multirow{2}{*}{ Physical Abuse } & Yes & 48 & 36.1 \\
\hline & No & 85 & 63.9 \\
\hline \multirow{2}{*}{$\begin{array}{l}\text { History of mood } \\
\text { disorder }\end{array}$} & Yes & 2 & 1.5 \\
\hline & No & 131 & 98.5 \\
\hline
\end{tabular}

A total of 133 women were evaluated for depression using the PHQ-9 tool. Thirty-seven women who scored a cut off of 10 and above on the PHQ -9 scale were diagnosed with Major Depressive Disorder, amounting to a prevalence of $27.8 \%$ for Major Depressive Disorder 27.8\%. Among the 37 women who had Major Depressive Disorder,73\% had mild depression, $16 \%$ had moderate depression, and $11 \%$ had severe depression.

Depressive disorder was more common in wives of men who consumed alcohol for more than five years, but the association was not statistically significant $(\mathrm{p}=1$ by Fisher's exact). Depressive disorder was more common in wives of men who had withdrawal symptoms, but the association was not statistically significant $(\mathrm{p}=1$ by Fisher's exact). 
Table 3.Association between severity of alcohol use of husbands and depression in wives ( $N=$ )

\begin{tabular}{|c|c|c|c|c|c|c|c|}
\hline \multirow{3}{*}{$\begin{array}{l}\text { DSM } 5 \text { diagnosis } \\
\text { AUD (husband) }\end{array}$} & \multicolumn{4}{|c|}{ Depression(wife) } & \multirow{3}{*}{$\chi^{2}$} & \multirow{3}{*}{$\mathrm{df}$} & \multirow{3}{*}{ p-value } \\
\hline & \multicolumn{2}{|c|}{ Yes } & \multicolumn{2}{|c|}{ No } & & & \\
\hline & $\mathrm{N}$ & $\%$ & $\mathrm{~N}$ & $\%$ & & & \\
\hline Mild & 3 & 8.1 & 9 & 9.4 & & & \\
\hline Moderate & 2 & 5.4 & 28 & 29.2 & 9.177 & 2 & $0.010^{*}$ \\
\hline Severe & 32 & 86.5 & 59 & 61.5 & & & \\
\hline
\end{tabular}

A significant association was seen between the severity of alcohol use of husbands and depression in their wives $(\mathrm{OR}=4.01,95 \% \mathrm{CI}=1.44-11.22, \mathrm{p}<0.05)$ (Table 3). A significant association was also noted between morning drinking of husband and depression in wives $(\mathrm{OR}=4.32,95 \% \mathrm{CI}=1.32-19.56, \mathrm{p}<0.05)($ Table 4$)$

Table 4. Association between morning drinking of husbands and depression in wives

\begin{tabular}{lcccccccc}
\hline \multirow{2}{*}{$\begin{array}{c}\text { Morning } \\
\text { drinking }\end{array}$} & \multicolumn{9}{c}{ Yes } & \multicolumn{2}{c}{ No } & \multirow{2}{*}{$\chi^{2}$} & df & $\begin{array}{c}\mathrm{p}- \\
\text { value }\end{array}$ \\
\cline { 2 - 5 } & $\mathrm{N}$ & $\%$ & $\mathrm{~N}$ & $\%$ & & & \\
\hline Yes & 35 & 94.6 & 77 & 80.2 & 4.16 & 1 & 0.041 \\
No & 2 & 5.4 & 19 & 19.8 & & & \\
\hline $\mathrm{X}^{2}$ - Chi-square value. df- degrees of freedom. ${ }^{*} \mathrm{p}<0.05$ & &
\end{tabular}

The other sociodemographic and clinical variables did not show a significant association with depression in the wife.

\section{DISCUSSION}

The current study was done to estimate the prevalence of Major Depressive Disorder among wives of men with Alcohol Use Disorder attending the Psychiatry department of Government Medical College, Thiruvananthapuram.

The Prevalence of Major Depressive Disorder in the wives was $27.8 \%$ in the present study. Among the 37 women who had Major Depressive Disorder, two had a past history of mood disorder. PHQ-9 tool though sensitive to screen and diagnose current Major Depressive Disorder, ${ }^{18}$ does not rule out Dysthymia and Bipolar Depression. This study being cross-sectional, all women who scored a cut off of 10 and above with the PHQ-9 scale were diagnosed as having Major Depressive Disorder irrespective of their previous mood episodes.

A significant association was seen between the severity of Alcohol Use Disorder of the husband and Major
Depressive Disorder in the wives $(\mathrm{OR}=4.01$, $95 \% \mathrm{CI}=1.44-11.22, \mathrm{p}<0.01)$. A significant association was also noted between morning drinking of husband and depression in wives $(\mathrm{OR}=4.32,95 \% \mathrm{CI}=1.32-19.56$, $\mathrm{p}=0.040$ ). These findings are in concordance with other studies conducted in India and neighbouring countries $^{9,12}$

A Sri Lankan study by Aryasinghe et al. in $2008^{12}$ reported a point prevalence of $33.3 \%$ of Major Depressive Disorder in spouses of men with Alcohol Use Disorder. Severe alcohol Use and morning drinking were also positively associated with depressive disorder. Morning drinking of the husband increased the odds of depression ( $\mathrm{OR}=4.11, \mathrm{C} . \mathrm{I}=1.01-1.09$; $\mathrm{p}=0.0003$ ) which is comparable to our study

A study done at a tertiary care centre at Assam among spouses of men with Alcohol Dependence Syndrome by Ghosh et al. in 2017 reported a prevalence of $30.43 \%$ for depressive disorders. ${ }^{14}$ This study which used ICD 10 criteria for diagnosing Alcohol Dependence syndrome and Depressive disorder, is comparable to our study.

Comparable results were obtained in another Kerala based study conducted in 2017 by Archana et al. ${ }^{15}$ The Prevalence of Major Depressive Disorder in wives of men with Alcohol Use Disorder was 26.5\% in this study.

Compared to our study, a study from Maharashtra by Bagul et al. in 2015 reported a low prevalence of $13.33 \%$ for depression in spouses of men with Alcohol Use Disorder. ${ }^{9}$ This study assessed only outpatients and used SCID 1 as tool for depression. This tool has lower sensitivity and higher specificity compared to PHQ 9, hence the lower prevalence rates.

A high prevalence rate of $97 \%$ for depressive symptoms in spouses was reported by Padmavathi et al. ${ }^{10}$ in Tamil Nadu. This study had a low sample size of 30, the population was from a de-addiction centre, and the tool used was the Centre for Epidemiological Studies 
Depression Scale. These could be the reasons for the high prevalence rate compared to our study. ${ }^{8}$

Various sociodemographic and clinical variables did not show any significant association with depression in the spouse. $36.1 \%$ of the study population reported a history of physical violence. A positive correlation was found between the history of physical abuse in wives and the prevalence of depression, but it was insufficient to establish clinical significance. $(p=0.06)$. Campbell had identified depression as major morbidity in women with a history of physical abuse. ${ }^{19}$ The clinical insignificance in our study could be due to cultural differences from the western population, low sample size and lack of a structured tool for assessing physical abuse.

\section{LIMITATIONS}

This study design is cross-sectional; hence causal relationships cannot be assessed. Major Depressive Disorder was diagnosed based on cross-sectional assessment using PHQ-9. PHQ -9 does not rule out Bipolar Depression. The results are from a tertiary care teaching centre, hence cannot be generalized to the population at large.

\section{CONCLUSIONS}

The Prevalence of Major Depressive Disorder among wives of men with Alcohol Use Disorder was estimated to be $27.8 \%$. Depression in the wives was significantly associated with the severity of Alcohol Use Disorder in the husband

Depression in the wife was significantly associated with morning drinking of the husband.

\section{Source of funding}

NIL

\section{Conflict of interests}

None

\section{REFERENCES}

1. Das SK, Balakrishnan V, Vasudevan DM. Alcohol: its health and social impact in India. Natl Med J India. 2006 Mar-Apr;19(2):94-9. PMID: 16756199

2. Ambekar A, Agrawal A, Rao R, Mishra AK, Khandelwal SK. Magnitude of Substance Use in India. New Delhi: Ministry of Social Justice and Empowerment, Government of India; 2019. on Behalf of the Group of Investigators for the National Survey on Extent and Pattern of Substance Use in India.
3. Bhullar, D. S., Singh, S. P., Thind, A. S., Aggarwal, K. K., \& Goyal, A. (2013). Alcohol Drinking Patterns: A 4. Sample Study. J Indian Acad Forensic Med [serial online] Mar, 35(1), 0971-097.

4. K Vidhukumar, E Nazeer, P Anil . Prevalence and pattern of alcohol use in Kerala - A district based survey International Journal of Recent Trends in Science and Technology. March 2016; 18(2): 363-367

5. World Health Organisation. Global status report on alcohol and health 2014. 2014; 1-392.

6. International Institute for Population Sciences (IIPS) and Macro International. 2008. National Family Health Survey (NFHS-3), India 2005-06: Kerala. Mumbai: IIPS.

7. Dawson DA, Grant BF, Chou SP, Stinson FS. The impact of partner alcohol problems on women's physical and mental health. J Stud Alcohol Drugs. 2007 Jan;68(1):66-75

8. Kogan KL, Jackson JK. Stress, personality and emotional disturbance in wives of alcoholics. Q J Stud Alcohol. 1965 Sep;26(3):486-95. PMID: 5858253.

9. Bagul KR, Deshmukh SB, Bagul MK, Deshmukh PS. Psychiatric morbidity and marital quality among wives of patients with alcohol dependence syndrome. J Evid Based Med Healthc. 2015;2:3284-95

10. Padmavathi, P, Jemila, I., Devi, J., Maragatham, M., Suganya, S., \& Prakash, V. Co-Dependency and Depressive Symptoms among Wives of Alcoholics Selected in Hospital, Erode. Int. J. Adv. Nur. Management 2(3): July-Sept.,2014; 143-6.

11. Nayak MB, Patel V, Bond JC, Greenfield TK. Partner alcohol use, violence and women's mental health: Population-based survey in India. Br J Psychiatry. 2010; 196: 192-199.

12. Ariyasinghe $\mathrm{D}$, Abeysinghe $\mathrm{R}$, Siriwardhana $\mathrm{P}$, Dassanayake T. Prevalence of major depressive disorder among spouses of men who use alcohol in a rural community in Central Sri Lanka. Alcohol Alcohol. 2015;50(3):328-332.

13. Kishor M, Pandit LV, Raguram R. (2013) Psychiatric morbidity and marital satisfaction among spouses of men with alcohol dependence. Indian J Psychiatry 55:360-5.

14. Ghosh P, Victor R, Das H, Sharma S. Psychiatric morbidity and marital satisfaction: an empirical study on spouse of alcohol dependent cases in Barak valley, North-East India. Int J Res Med Sci 2017;5:1600-6.10

15. Archana, P.S.; Das, S.; Philip, S.; Philip, R.R.; Joseph, $\mathrm{J}$.; Punnoose et al. prevalence of depression among middle aged women in the rural area of Kerala. Asian J. Psychiatry 2017, 29, 154-159.

16. American Psychiatric Association. Diagnostic and statistical manual of mental disorders. 5th ed. 
Washington, DC: American Psychiatric Association; 2013

17. Gilbody S, Richards D, Brealey S, Hewitt C: Screening for depression in medical settings with the Patient Health Questionnaire (PHQ): a diagnostic metaanalysis. J Gen Intern Med. 2007, 22: 1596-1602.

18. Poongothai S, Pradeepa R, Ganesan A, Mohan V. Reliability and validity of a modified PHQ-9 item inventory (PHQ-12) as a screening instrument for assessing depression in Asian Indians (CURES-65). J Assoc Physicians India. 2009 Feb;57:147-52. PMID: 19582982.

19. Campbell JC, Kub J, Belknap RA, Templin TN. Predictors of Depression in Battered Women. Violence Against Women. 1997; 3(3):271-293. 